(51.7\%) followed by men in 60-64 (30\%) and 75-79 (16.3\%) age group.

\begin{tabular}{lccc}
\hline & $\mathbf{1 9 8 7 - 1 9 8 9}$ & $\mathbf{1 9 9 3 - 1 9 9 7}$ & $\mathbf{2 0 0 2 - 2 0 0 7}$ \\
\hline Cases & $\mathbf{2 5}$ & 71 & 192 \\
$\%$ & 3.7 & 5.2 & 9.4 \\
ASR (100 000 males) & 2.9 & 4.3 & 8.2 \\
\hline
\end{tabular}

Age-adjusted incidence rate increased quickly from 2.9 per 100000 men to 8.2 per 100000 men in 2002-2007

Conclusion It represents $9.4 \%$ of all cancers reported in Setif. The results suggest that the prostate cancer ranked second among male population and the age-adjusted incidence rate increased quickly during these 2 decades.

\section{SP1-110 LUNG CANCER INCIDENCE AND TRENDS IN SETIF, ALGERIA BETWEEN 1986 AND 2008}

doi:10.1136/jech.2011.142976n.87

${ }^{1}$ Z Zoubida, ${ }^{2} \mathrm{M}$ Abdehak, ${ }^{1} \mathrm{~L}$ Slimane, ${ }^{3} \mathrm{~A}$ Djemal, ${ }^{1} \mathrm{M}$ Hamdi Cherif. ${ }^{1}$ Cancer registry of Setif, University hospital of Setif, Setif, Algeria; ${ }^{2}$ Department of pulmonary medicine, University hospital of Setif, Setif, Algeria; ${ }^{3}$ Anatomopathology Department, University hospital of Setif, Setif, Algeria

Background Lung cancer is the most frequent malignant neoplasm among men in most countries and represents the most important cause of cancer death worldwide, it accounts for an estimated 960000 new cases and 850000 deaths each year among men. In most populations, tobacco smoking accounts for $80 \%$ or more lung cancers. This study was designed to provide up-dated incidence figures for lung cancer in Setif at the period 1986-2008 adjusting for the effect of age, sex, and period of diagnosis and the geographical distribution of lung cancer at the national international level.

Material and Method Cancer registry represents a data source, the software used is the Can Reg 4 produced by the unit of descriptive epidemiology of the International Agency for Research on Cancer IARC, Lyon. France.

Results There were 188 cases of lung cancer registered during 2006-2008 representing 16.8\% of all cases among males. Incidence was highest among 80-85 age group with 122/100 000 followed by men in 85-90 with 45, 5/100000 for men. The median age at diagnosis was $65-69$ age group. The age-standardised rates increase from 11.7 to 23,8 per 100000 men these 2 decades.

Conclusion Between 1986 and 2008, the study showed a large change in the cancer burden both quantitatively and qualitatively. This evolution was due to demographic changes and an increase in the risk factors of cancer during this period 1986-2008.

\section{SP1-111 TRENDS IN BREAST CANCER INCIDENCE IN SETIF, ALGERIA BETWEEN 1987 AND 2007}

doi:10.1136/jech.2011.142976n.88

${ }^{1}$ Z Zoubida, ${ }^{*}$ A Djemal, ${ }^{3} \mathrm{D}$ D Aicha, ${ }^{1} \mathrm{~L}$ Slimane, ${ }^{1} \mathrm{M}$ Hamdi Cherif. ${ }^{1}$ Cancer registry of Setif, University Hospital of Setif, Setif, Algeria; ${ }^{2}$ Department of Anatomopathology, University Hospital of Setif, Setif, Algeria; ${ }^{3}$ Constantine Anti Cancer Center, University Hospital of Constantine -Algeria, Constantine, Algeria

Introduction Breast cancer is the most common cancer in women worldwide. It was estimated that 636000 incidents cases occurred in developed countries and 514000 in developing countries during 2002. Breast cancer is also the most important cause of neoplasic deaths among women; the estimated number of deaths in 2002 was 410000 worldwide. Our study aimed for adjusting breast cancer incidence trends over the longest period available 1987-2007 in Setif for the effect of age and period of diagnosis.

Material and Method Incidence datas were collected in the period 1987-2007 from the population-based cancer registry of Setif, the software used is the Can Reg 4.

Results Breast cancer ranked first among female population. Incidence was highest among women $30-55$ age group (63\%), the median age at diagnosis was $54-59$ age group.

\begin{tabular}{lccc}
\hline & $\mathbf{1 9 8 7 - 1 9 8 9}$ & $\mathbf{1 9 9 3 - 1 9 9 7}$ & $\mathbf{2 0 0 5 - 2 0 0 7}$ \\
\hline Cases & 187 & 317 & 224 \\
$\%$ & 10.3 & 22.2 & 21.1 \\
ASR (100 000 females) & 10.4 & 17.0 & 24.8
\end{tabular}

Age-adjusted incidence rate increased in this 2 decades from 10.4 per 100000 women in $1987-1989$ to 24.8 per 100000 women in 2005-2007.

Conclusion It is the most common cancer it represents $21,1 \%$ of all cancer sites reported in Setif cancer registry, more than $50 \%$ of new cases are the young women whose age is inferior at 40 years. It represents the first cause of mortality at women in Algeria it accounts 7000 deaths each year. The results suggest that the early detection should become a priority in Algeria.

\section{SP1-112 PREVALENCE OF HYPERTENSION AMONG BANGLADESHI ADULT POPULATION: A META-ANALYSIS}

doi:10.1136/jech.2011.142976n.89

${ }^{1} \mathrm{M}$ Zaman, ${ }^{1} \mathrm{~A}$ Taleb, ${ }^{1} \mathrm{~S}$ Rahman, ${ }^{1} \mathrm{~A}$ Acharyya, ${ }^{1} \mathrm{~F}$ A Islam, ${ }^{1} \mathrm{M}$ S A M Ahmed, ${ }^{*}$ ${ }^{2} \mathrm{M}$ Zaman. ${ }^{1}$ Bangladesh Institute of Health Sciences, Dhaka, Bangladesh; ${ }^{2}$ World Health Organization, Dhaka, Bangladesh

Background Hypertension is recognised as a major contributor to disease burden globally affecting $20 \%$ of adult population. More importantly it has become a significant problem in many developing countries experiencing epidemiological transition from communicable to non-communicable chronic diseases.

Objective The study was to determine the prevalence of hypertension among Bangladeshi adult population by meta-analysis.

Method In this meta-analysis the articles published during the period from 1995 to 2009 on the prevalence of hypertension among Bangladeshi adult population were identified by MEDLINE search included. We included those population based studies for this meta-analysis who clearly defined the diagnostic definition of hypertension and the age group ( $\geq 18$ years). We could locate thirteen articles, among them seven articles were excluded from the current analysis because they did not fulfil our selection criteria Then the prevalence of hypertension and their 95\% CIs $(\mathrm{p} \pm 1.96 \sqrt{\mathrm{pq}} / \mathrm{n})$ for the individual studies were calculated by using the data presented. Finally a pooled estimate was obtained from six studies.

Result The pooled estimates for the prevalence of hypertension in 6430 adults are $13.5 \%$ (with $95 \%$ CI $12.66 \%$ to $14.34 \%$ ).

Conclusion This meta-analysis clearly demonstrated that $13.5 \%$ adult population were at risk to develop cardiovascular and kidney diseases and this underscored the importance of screening of asymptomatic yet potentially harmful hypertensive disorders to combat the growing epidemic of Non-communicable Diseases.

Recommendation Large scale studies can be done including all the high risk population to represent the actual scenario of hypertension in Bangladeshi adult population. 